\title{
Apresentação das lesões mamárias císticas à ultra-sonografia utilizando a elastografia*
}

\author{
Features of cystic breast lesions at ultrasound elastography \\ Eduardo de Faria Castro Fleury ${ }^{1}$, José Francisco Rinaldi ${ }^{2}$, Sebastião Piato ${ }^{3}$, \\ José Carlos Fleury ${ }^{4}$, Décio Roveda $\mathrm{Jr}^{5}$
}

Resumo OBJETIVO: Demonstrar a apresentação mais freqüente das lesões mamárias císticas utilizando a elastografia e discutir a sua aplicabilidade. MATERIAIS E MÉTODOS: A casuística compôs-se de 150 pacientes encaminhadas para realização de biópsia mamária percutânea com 175 lesões. Foram excluídas as lesões com diagnóstico histológico de lesões sólidas (153 lesões) e incluídas as lesões com características císticas à histologia (22 lesões), incluindo cistos complicados, lesões papilíferas, lesões inflamatórias, hiperplasia de células colunares típica e ectasia ductal. Estas lesões foram classificadas de forma retrospectiva por meio da elastografia, conforme escores criados pelos autores, variando de 1 a 4 . RESULTADOS: Das 22 lesões encaminhadas, $13(59 \%)$ correspondiam a cistos, uma $(4,6 \%)$ a ectasia ductal, duas $(9,2 \%)$ a lesões inflamatórias, cinco $(22,6 \%)$ a lesões papilíferas e uma $(4,6 \%)$ a hiperplasia de células colunares. Foram encontrados 17 escores 2, quatro escores 3, um escore 4 e nenhum escore 1, com especificidade de 95\%. CONCLUSÃO: As lesões císticas mamárias têm diferentes apresentações à elastografia, conforme o resultado histológico, sendo este um método útil para a sua diferenciação e de fácil aplicabilidade na clínica diária. Unitermos: Cisto mamário; Ultra-sonografia; Mama.

Abstract OBJECTIVE: To demonstrate the most frequent features of cystic breast lesions at ultrasound elastography, discussing the applicability of this method. MATERIALS AND METHODS: The present casuistic included 150 patients referred for percutaneous breast biopsy of 175 lesions. Histologically diagnosed solid lesions (153 lesions) were excluded; lesions histologically diagnosed as cystic (22 lesions), including complicated cysts, papillary lesions, inflammatory lesions, typical columnar cell hyperplasia and duct ectasia were retrospectively classified by means of elastography, according to a scoring system developed by the authors, with categories ranging between 1 and 4. RESULTS: Thirteen (59\%) of the 22 lesions evaluated corresponded to cysts, one $(4.6 \%)$ to duct ectasia, two $(9.2 \%)$ to inflammatory lesions, five $(22.6 \%)$ to papillary lesions, and one $(4.6 \%)$ to columnar cell hyperplasia. The scoring system was applied with the following results: 17 category 2 lesions, four category 3 lesions, one category 4 lesion, and none category 1 lesion, with a 95\% specificity. CONCLUSION: Different features of cystic breast lesions are demonstrated by elastography according to histological results, representing a useful and easily applicable method for differentiating benign from malignant breast lesions. Keywords: Breast cyst; Ultrasonography; Breast.

Fleury EFC, Rinaldi JF, Piato S, Fleury JC, Roveda Jr D. Apresentação das lesões mamárias císticas à ultra-sonografia utilizando a elastografia. Radiol Bras. 2008;41(3):167-172.

* Trabalho realizado na Faculdade de Ciências Médicas da Santa Casa de São Paulo, São Paulo, SP, Brasil.

1. Pós-graduando, Médico Segundo Assistente da Santa Casa de São Paulo, São Paulo, SP, Brasil.

2. Professor Assistente, Chefe da Clínica de Mastologia do Departamento de Obstetrícia e Ginecologia da Irmandade da Santa Casa de Misericórdia de São Paulo, São Paulo, SP, Brasil.

3. Professor Titular, Chefe da Clinica Ginecológica do Departamento de Obstetrícia e Ginecologia da Irmandade da Santa Casa de Misericórdia de São Paulo, São Paulo, SP, Brasil.

4. Especialista em Diagnóstico de Imagem, Coordenador do Serviço de Intervenção Mamária do Centro de Tomografia Computadorizada - CTC Gênese, São Paulo, SP, Brasil.

5. Professor Instrutor, Diretor do Serviço de Diagnóstico por Imagem da Santa Casa de São Paulo, São Paulo, SP, Brasil.

Endereço para correspondência: Dr. Eduardo de Faria Castro Fleury. Alameda Ministro Rocha Azevedo, 1368, ap. 52, Jardins. São Paulo, SP, Brasil, 01410-002. E-mail: edufleury@hotmail. com

Recebido para publicação em 23/8/2007. Aceito, após revisão, em 16/10/2007.

\section{INTRODUÇÃO}

A ultra-sonografia mamária foi difundida na década de 80 como método auxiliar na diferenciação de lesões mamárias sólidas de císticas, auxiliando no diagnóstico de nódulos mamários caracterizados à mamografia $^{(\mathbf{1})}$. A partir da década de 90 , com a introdução de sondas de maior freqüência, a ultra-sonografia proporcionou não só diferenciar as lesões sólidas de císticas, como realizar uma análise criteriosa das lesões encontradas, firmando-se como método adjuvante no arsenal propedêutico da mama, até os dias atuais, quando é proposto por alguns autores como estudo de rastreamento de câncer de mama para mulheres jovens que apresentaram mamas densas na mamografia (categorias de tecido pelo léxico BI-RADS ${ }^{\circledR} 3$ e 4$)^{(2-4)}$.

Um dos problemas decorrentes da difusão do ultra-som como método de rastreamento nestas pacientes foi a visualização de novas alterações no tecido mamário que geralmente não estão relacionadas com malignidade. Muitos nódulos, que muitas vezes não eram visualizados, passaram a ser vistos, geralmente associados com benignidade, como a presença de cistos com conteúdo espesso (cistos complicados). Estes cistos apresentam dificuldade na distinção, apenas pelo estudo convencional, 
de nódulos sólidos verdadeiros, cujas condutas são diferentes, e são geralmente classificados como nódulos indeterminados, causando ansiedade nas pacientes, que acabam optando pela realização de biópsias mamárias diagnósticas ${ }^{(5,6)}$.

Um dos grandes desafios da ultra-sonografia é promover a distinção destas duas entidades sem acarretar aumento de custo ou de realização de procedimentos intervencionistas. Estudos vêm sendo realizados sobre métodos complementares à ultra-sonografia que poderiam melhorar a sua acurácia, como o Doppler-fluxométrico, o desenvolvimento de imagens harmônicas, a elastografia e o estudo por meio do frêmito $^{(7-10)}$

$\mathrm{O}$ presente estudo vem demonstrar a apresentação pela elastografia, por intermédio da classificação criada pelos autores, das mais diversas lesões císticas encontradas em um estudo ultra-sonográfico em pacientes que foram encaminhadas ao serviço para a realização de biópsias diagnósticas, e discutir a sua aplicabilidade clínica.

\section{MATERIAIS E MÉTODOS}

Este estudo foi aprovado pelo Comitê de Ética Institucional, retrospectivo, realizado no Serviço de Diagnóstico por Imagem da Santa Casa de Misericórdia de São Paulo, SP, sendo avaliados os resultados histológicos de 150 pacientes com idade média de 45 anos (variação entre 24 e 70 anos) que apresentavam 170 lesões ao estudo ultra-sonográfico convencional, encaminhadas para a realização de biópsia mamária percutânea ao Centro de Tomografia Computadorizada, no período de $1^{\circ}$ de maio a 30 de julho de 2007. O diâmetro médio das lesões foi de $1,4 \mathrm{~cm}$ (mediana de $1,2 \mathrm{~cm}$, variação de $0,5 \mathrm{~cm}$ a $3,2 \mathrm{~cm}$ ).

Foram excluídas 130 pacientes com 148 lesões que se apresentaram exclusivamente sólidas à histologia. Foram incluídas 20 pacientes com 22 lesões que tiveram resultados histológicos de lesões puramente císticas (como cistos complicados), lesões inflamatórias e ectasia ductal, ou císticas associadas a componentes sólidos, como lesões papilíferas e hiperplasia de células colunares típicas, provenientes de 17 $(91,9 \%)$ biópsias por fragmento e $5(8,1 \%)$ localizações pré-operatórias via reparo.

\section{Diagnóstico patológico}

Os materiais obtidos foram encaminhados para estudo histológico e foram analisados por uma patologista especialista em lesões mamárias, com experiência de 17 anos. As lesões foram divididas em cistos, lesões papilíferas, lesões inflamatórias, hiperplasia de células colunares típica e ectasia ductal $^{(\mathbf{1 1 , 1 2})}$.

\section{Equipamento}

Tanto o estudo convencional como a elastografia foram realizados pelo mesmo radiologista, com seis anos de experiência em imaginologia mamária, utilizando um sistema de ultra-som Sonix SP (Ultrasonix Medical Corporation; Vancouver, Canadá) com sonda multifrequiencial linear de 5 $\mathrm{MHz}$ a $14 \mathrm{MHz}$.

Para o estudo da elastografia foi utilizado software especial para o aparelho da Ultrasonix, versão 3.0.2 (Beta 1), cujos direitos de utilização experimental para a pesquisa foram concedidos ao autor principal durante o período de estudo.

Nenhuma paciente deste estudo preliminar apresentou reações adversas ao método.

\section{Técnica}

Primeiramente, foi realizado o estudo convencional das mamas, com as pacientes posicionadas em decúbito dorso-horizontal e as mãos sob a cabeça, obtendo-se imagens no modo B e Doppler colorido, para avaliação de vascularização dos nódulos, seguindo os critérios do léxico BIRADS $^{\circledR}$. As medidas foram realizadas pelo modo B nos eixos longitudinal e ânteroposterior, considerando para a análise a maior medida.

Logo após o estudo convencional, foi realizada a elastografia, com a paciente na mesma posição do primeiro estudo e com o transdutor orientado perpendicularmente à lesão. Antes de sua execução foram realizadas compressões sobre a lesão, para certificar o não-deslocamento lateral desta. Após ativar a elastografia, realizaram-se compressões e descompressões seriadas na área de interesse, compressões não-superiores a $1 \%$ da espessura total da mama, sendo que o examinador pôde monitorar em tempo real o comportamento da força aplicada. A área de estudo selecionada incluiu desde o tecido celular subcutâneo até o músculo peitoral e as adjacências do nódulo por até $0,5 \mathrm{~cm}$. Após a obtenção das imagens, foi realizada reavaliação do estudo por meio do cinememory. O tempo de exame elastográfico não excedeu a cinco minutos.

\section{Análise ultra-sonográfica}

A análise do estudo ultra-sonográfico convencional foi realizado utilizando critérios de acordo com o léxico BI-RADS ${ }^{\circledR}$, no qual nódulos anecóides com bordas circunscritas e imperceptíveis e com reforço acústico posterior são classificados como cistos simples ${ }^{(\mathbf{1 3})}$; cistos complicados, quando o conteúdo interno é homogêneo, de paredes pouco espessadas, com finos débris em suspensão ou finos septos de permeio e reforço acústico posterior; lesões indeterminadas, quando o conteúdo é homogêneo e com finos ecos de permeio, sem reforço acústico posterior evidente e sem a diferenciação de bordas; lesões císticas complexas, quando apresentam septos grosseiros, maiores que $0,5 \mathrm{~mm}$ ou quando apresentam nódulo mural ocupando menos que $50 \%$ do cisto; nódulos, quando o componente sólido é superior a $50 \%$ do componente cístico.

Não foi considerado nenhum cisto de aspecto simples neste estudo, devido à recomendação do léxico BI-RADS ${ }^{\circledR}$ de classificá-los na categoria $2^{(\mathbf{1 4 , 1 5 )}}$.

\section{Classificação pela elastografia}

A elastografia consiste na variação do espectro de cores conforme a elasticidade dos diversos tecidos presentes em uma amostragem ultra-sonográfica, em que o vermelho é referente a tecidos mais macios, como a gordura, o amarelo e o verde para tecidos intermediários, e o azul para tecidos rígidos, como lesões hipercelulares ou com intensa fibrose (Figura 1$)^{(\mathbf{1 6})}$

A classificação elastográfica proposta incluiu quatro escores, de acordo com a variação da cor durante a compressão e após a descompressão da área de interesse. $\mathrm{O}$ escore 1 foi atribuído às lesões que apresentaram o mesmo espectro de cores do tecido mamário circunjacente. $\mathrm{O}$ escore 2 foi dado às lesões que, após a descompressão, mostraram variação de cor para mais macia 

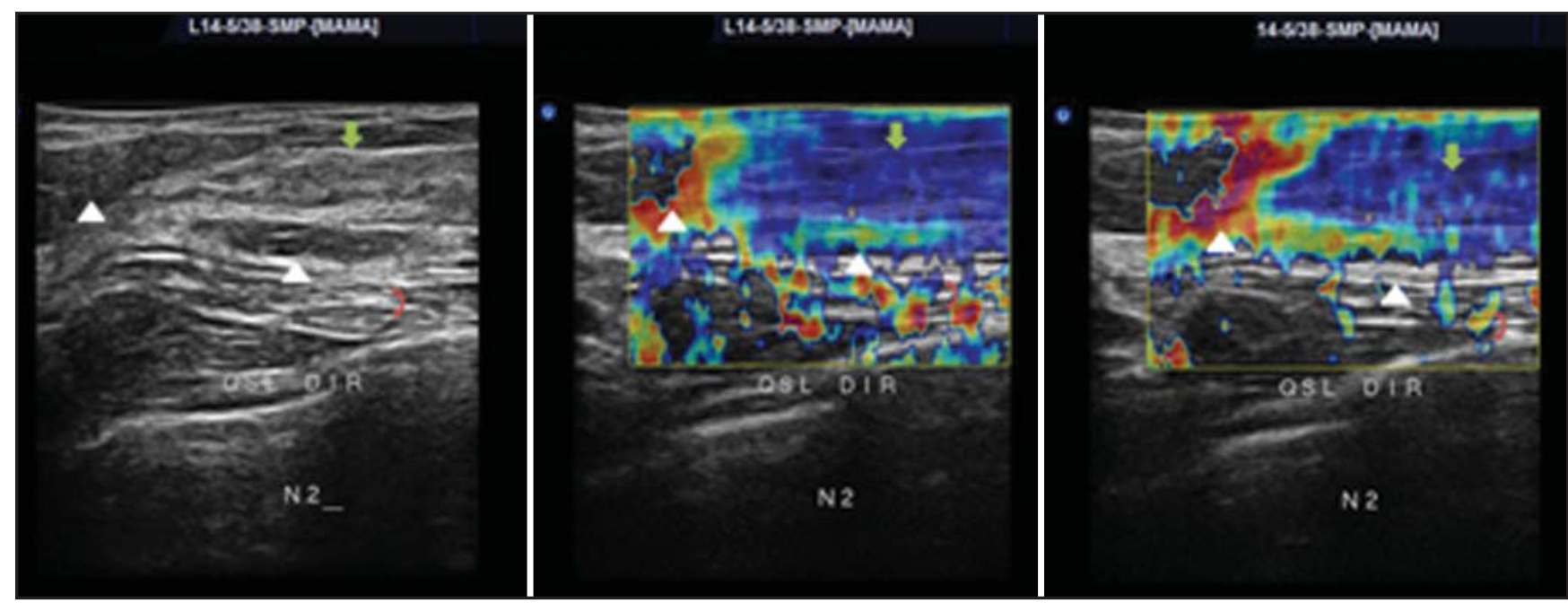

Figura 1. Amostra de tecido mamário normal ao modo convencional (imagem da esquerda), utilizando a elastografia durante a compressão (imagem central) e após a descompressão (imagem da direita). As pontas de setas demonstram tecido fibroadiposo, a seta reta aponta para o tecido glandular normal e a seta curva demonstra a musculatura peitoral.

abrangendo mais que $50 \%$ do nódulo, ou seja, após a descompressão uma área superior à metade do nódulo apresentou coloração variando pela escala de verde a vermelho. $\mathrm{O}$ escore 3 foi atribuído às lesões que, após a descompressão, apresentaram variação de cor em menos de $50 \%$ da área do nódulo (entre 10\% e 50\%), geralmente na periferia deste, variando de amarelo para verde pela escala de "cores". Por fim, o escore 4 foi dado às lesões que não apresentaram variação significativa na cor durante a compressão e após a descompres- são, permanecendo azul nas duas imagens. Foram considerados benignos os escores 1 e 2, baixa probabilidade de malignidade $o$ escore 3 e alta probabilidade de malignidade o escore 4 (Quadro 1).

\section{RESULTADOS}

\section{Diagnóstico patológico}

Das 22 lesões apresentadas, 13 (59\%) correspondiam a cistos apócrinos, uma $(4,6 \%)$ a ectasia ductal, duas $(9,2 \%)$ a lesões inflamatórias, cinco $(22,6 \%)$ a lesões papilíferas e uma $(4,6 \%)$ a hiperplasia de células colunares.

\section{Apresentação ultra-sonográfica}

Os 13 cistos apócrinos apresentaram-se como nódulos indeterminados. A ectasia ductal e as duas lesões inflamatórias apresentaram-se como cistos complicados. Das cinco lesões papilíferas, três $(60 \%)$ apresentaram-se como nódulos indeterminados e duas (40\%) como cistos complexos, e a hiperplasia de células colunares apresentou-se como cisto complexo (Tabela 1).

Quadro 1 Classificação pela elastografia por meio de escores conforme apresentação pelo espectro de cores durante a compressão da amostra e após a descompressão.

\begin{tabular}{|clll|}
\hline Escore & \multicolumn{1}{|c}{ Durante a compressão } & \multicolumn{1}{c|}{ Descompressão } & Resultado \\
\hline 1 & Cor semelhante ao tecido normal & Cor semelhante ao tecido normal & Benigno \\
2 & $\begin{array}{l}\text { Variação entre amarelo para azul esver- } \\
\text { deado }\end{array}$ & $\begin{array}{l}\text { Variação de cor para mais macia em mais } \\
\text { de 50\% do nódulo }\end{array}$ & Benigno \\
& $\begin{array}{l}\text { Variação entre azul esverdeado para azul } \\
3\end{array}$ & $\begin{array}{l}\text { Variação de cor para mais macia entre 10\% } \\
\text { escuro }\end{array}$ & Baixa probabilidade de malignidade \\
4 & Geralmente azul para azul escuro & Sem variação significativa & Alta probabilidade de malignidade \\
\hline
\end{tabular}

Tabela 1 Apresentação ultra-sonográfica das lesões císticas conforme o resultado histológico.

\begin{tabular}{lcccc}
\hline & \multicolumn{3}{c}{ Ultra-sonografia } \\
\cline { 2 - 4 } \multicolumn{1}{c}{ Resultado histológico } & $\begin{array}{c}\text { Nódulos } \\
\text { indeterminados }\end{array}$ & $\begin{array}{c}\text { Cistos } \\
\text { complicados }\end{array}$ & $\begin{array}{c}\text { Cistos } \\
\text { complexos }\end{array}$ & Total \\
\hline Cistos & 13 & - & - & 13 \\
Ectasia ductal & - & 1 & - & 1 \\
Inflamatório & - & 2 & - & 2 \\
Lesões papilíferas & 3 & - & 2 & 5 \\
Hiperplasia de células colunares & - & - & 1 & 1 \\
Total & 16 & 3 & 3 & 22 \\
\hline
\end{tabular}

\section{Apresentação à elastografia}

Dos 13 cistos apócrinos, todos foram classificados como escore 2 (Figura 2). A ectasia ductal e as lesões inflamatórias também foram classificadas como escore 2 . Das cinco lesões papilíferas, uma foi classificada como escore 2 e as outras quatro como escore 3 (Figura 3). Já a hiperplasia de células colunares foi classificada como escore 4 (Figura 4; Tabela 2). 

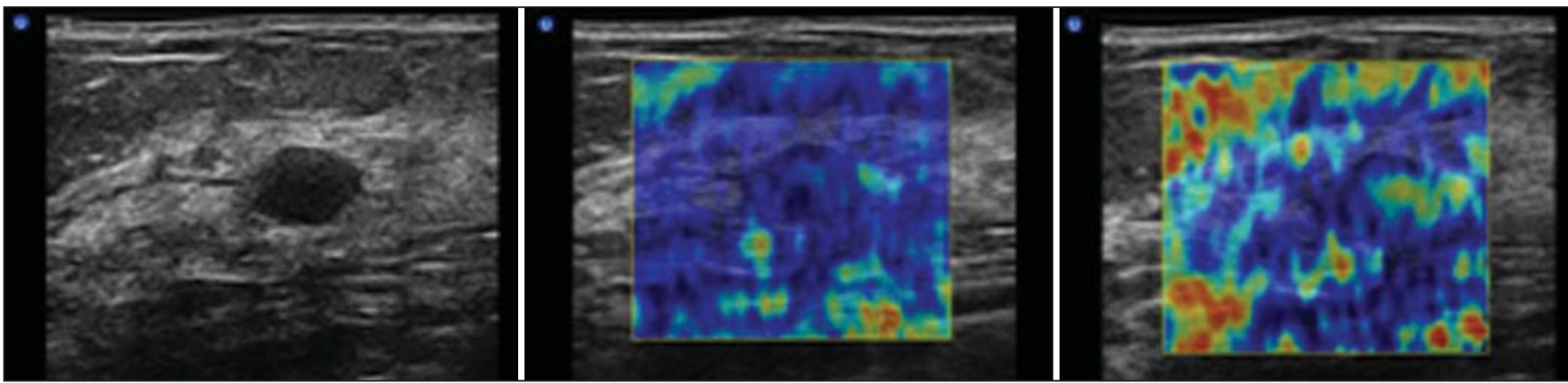

Figura 2. Exemplo de escore 2 pela elastografia. Nódulo indeterminado ao modo convencional (imagem da esquerda), utilizando a elastografia durante a compressão (imagem central) e após a descompressão (imagem da direita). Durante a compressão observa-se coloração central do nódulo azul-esverdeada: após a descompressão, observa-se o preenchimento de quase a totalidade do nódulo com coloração esverdeada.
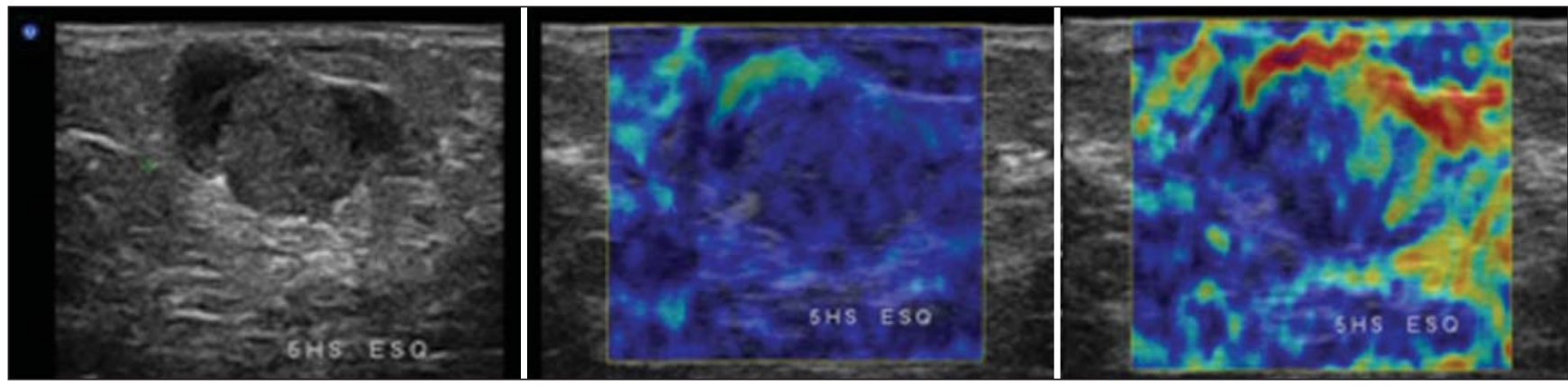

Figura 3. Exemplo de escore 3 pela elastografia. Cisto complexo ao modo convencional (imagem da esquerda) utilizando a elastografia durante a compressão (imagem central) e após a descompressão (imagem da direita). Durante a compressão observa-se coloração esverdeada na área cística periférica e azulada no nódulo mural; após a descompressão, observa-se a alteração da área cística para vermelho enquanto o nódulo mural apresenta alteração de cor em cerca de $10-50 \%$ para azul-esverdeado.
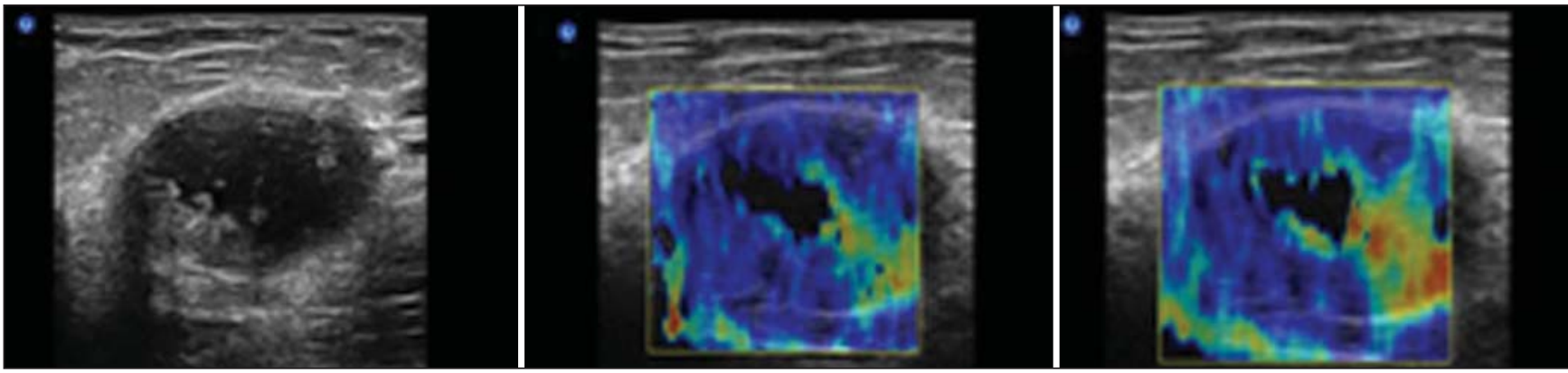

Figura 4. Exemplo de escore 4 pela elastografia. Cisto complexo ao modo convencional (imagem da esquerda) utilizando a elastografia durante a compressão (imagem central) e após a descompressão (imagem da direita). Durante a compressão observa-se coloração central do cisto como azul escuro/enegrecido e a parte sólida mural apresenta-se como azul; após a descompressão, observa-se a permanência da porção central como azul escuro/enegrecido e a parte sólida mural não apresenta alterações significativas. Nota-se ainda a mudança do componente cístico na borda inferior do nódulo, que apresentou variação de cor durante a compressão e após a descompressão.

Tabela 2 Apresentação pela elastografia das lesões císticas conforme o resultado histológico.

\begin{tabular}{lccccc}
\hline & \multicolumn{4}{c}{ Escores à elastografia } & \\
\cline { 2 - 5 } \multicolumn{1}{c}{ Resultado histológico } & 1 & 2 & 3 & 4 & Total \\
\hline Cistos & - & 13 & - & - & 13 \\
Ectasia ductal & - & 1 & - & - & 1 \\
Inflamatório & - & 2 & - & - & 2 \\
Lesões papilíferas & - & 1 & 4 & - & 5 \\
Hiperplasia de células colunares & - & - & - & 1 & 1 \\
Total & - & 17 & 4 & 1 & 22 \\
\hline
\end{tabular}

\section{DISCUSSÃO}

Há mais de uma década o método da elastografia vem ganhando bastante atenção para o estudo de tecidos moles, com a perspectiva clínica de poder detectar precocemente lesões que determinem alterações patológicas nos tecidos, proporcionando tratamento adequado para as lesões existentes e melhorando o prognóstico da paciente $^{(17)}$. As informações adquiridas são 
semelhantes às obtidas com a palpação manual, porém mais sensíveis e menos subjetivas $^{(\mathbf{1 8})}$.

O estudo pioneiro, realizado em 1991 por Ophir et al. ${ }^{(\mathbf{1 0})}$, propunha classificar os nódulos segundo a variação elástica, partindo do princípio que lesões benignas eram mais moles, enquanto a maioria das malignas era mais rígida. As imagens elastográficas eram obtidas pela comparação de imagens antes e após a compressão do tecido mamário. A partir de então, vários trabalhos vêm sendo publicados, porém sem nenhuma padronização de técnica ou classificação, a maioria utilizando apenas a comparação de imagens antes e após a compressão.

No entanto, nenhum trabalho descreve os achados nas alterações císticas da mama, que por muitas vezes podem criar angústia semelhante nas mulheres às de nódulos malignos, sendo que geralmente estão associadas a lesões benignas ou com baixo potencial de malignidade. Muitas destas lesões são interpretadas, no método convencional, como nódulos indeterminados, sendo necessário acompanhamento precoce, e invariavelmente acaba-se por realizar biópsias diagnósticas desnecessárias ${ }^{(19)}$.

As lesões císticas simples têm aspectos característicos ao ultra-som, apresentandose como nódulo circunscrito, de paredes imperceptíveis, com conteúdo anecóide e reforço acústico posterior, classificados como BI-RADS ${ }^{\circledR} 2$, enquanto as lesões sólidas se apresentam normalmente como nódulos ovóides, circunscritos, com orientação paralela à pele, classificados como BI-RADS 3. No entanto, nem todas as lesões císticas têm a mesma apresentação; algumas são de difícil distinção em relação a nódulos sólidos, principalmente quando apresentam conteúdo de líquido espesso no seu interior, por vezes com finos débris em suspensão, e são classificadas como nódulos indeterminados. Por terem baixo potencial de malignidade (cerca de $2 \%$ ), o acompanhamento precoce é recomendado como seguimento, porém de forma controversa e sem muito consenso. O protocolo de acompanhamento precoce mais utilizado é um novo estudo em um prazo de seis meses, direcionado à área parcialmente obscurecida à mamografia, e no caso de lesões ocultas à mamografia, é apenas realizada a ultra-sonografia. O próximo estudo de acompanhamento é realizado decorridos 12 meses do primeiro exame, porém sendo realizadas mamografia bilateral e ultra-sonografia das mamas, já que um ano é o prazo do rastreamento para o câncer de mama, sendo seguido por outro estudo após um ano deste último. Decorrido este período de dois anos, se a lesão permaneceu estável, a categoria final do BI-RADS é alterada para 2. Casos que apresentem aumento das dimensões em cerca de $10 \%$ do diâmetro inicial ou que apresentem alteração em suas margens são recomendados para a realização de biópsia percutânea ${ }^{(4,5,7)}$. Porém, para alguns autores, um nódulo sólido caracterizado apenas pelo ultra-som tem indicação de realizar biópsia diagnóstica, já que o ultra-som não permite diferenciar lesões benignas de malignas ${ }^{(20)}$. Acredita-se que esses achados incidentais à ultra-sonografia aumentam o número de biópsias negativas ${ }^{(\mathbf{2 1 , 2 2})}$.

Já os cistos complexos têm consenso quanto à realização de biópsia diagnóstica, tendo como padrão-ouro a biópsia excisional cirúrgica. Com a introdução da biópsia assistida a vácuo para o diagnóstico de lesões mamárias, esta passou a ter espaço no diagnóstico em tais lesões por ser de fácil realização, ambulatorial e com baixos índices de complicações. Nesses casos, a imagem ultra-sonográfica pelo modo B é determinante para a conduta a ser adotada, quando utilizados critérios descritivos seguindo o léxico BI-RADS. Nessas situações, há pouca controvérsia quanto à conduta a ser adotada ${ }^{(5)}$.

Para minimizar essa limitação do ultrasom, foi tentada a utilização de estudo Doppler-fluxométrico complementar e do uso de imagens harmônicas pelo modo-B, porém sem determinar incremento significativo em relação ao estudo convencional. Em estudos recentes utilizando um método chamado de frêmito, no qual se avalia a resposta do conteúdo interno do cisto à energia acústica criada pelo transdutor de ultrasom detectada pelo método Doppler, as lesões císticas apresentavam resposta ao Doppler, ao passo que as sólidas não. Está ainda sendo realizado de forma experimental e com poucos trabalhos publicados, mas pode vir a auxiliar na diferenciação desses nódulos indeterminados ${ }^{(7)}$
A elastografia, que idealmente foi introduzida ao estudo ultra-sonográfico para a diferenciação de lesões mamárias benignas de malignas, pode ser utilizada também para a diferenciação de lesões sólidas de císticas, tendo em vista que a elasticidade do cisto é maior que a do parênquima adjacente. Pode ainda ser útil para auxiliar na avaliação de cistos complexos, principalmente quando há nódulo mural, proporcionando determinar a rigidez desse nódulo. Neste estudo foi observado que todos os cistos diagnosticados histologicamente tinham apresentação ultra-sonográfica como nódulos indeterminados, e pela elastografia se apresentaram como escore 2, benignos. Os cistos com conteúdo inflamatório e a ectasia ductal tinham apresentação ultra-sonográfica como cistos complicados, e à elastografia apresentaram-se também como escore 2. Essas lesões tinham baixa possibilidade de serem malignas e as biópsias poderiam ter sido evitadas se fossem consideradas as apresentações pela elastografia associadas ao ultra-som.

Das lesões papilíferas, três $(60 \%)$ se apresentaram como nódulos indeterminados e duas (40\%), como cistos complexos ao estudo convencional; pela elastografia, uma $(20 \%)$ apresentou escore 2 e as outras quatro $(80 \%)$, escore 3. A lesão que apresentou escore 2 pela elastografia tinha apresentação ultra-sonográfica como nódulo indeterminado e media $0,5 \mathrm{~cm}$ no maior eixo. Esta lesão seria considerada como benigna pela elastografia e a paciente retornaria para o screening mamário, realizando o exame em um ano. No entanto, esta lesão foi submetida a excisão cirúrgica, que confirmou a sua benignidade. Das outras quatro $(80 \%)$ lesões com baixa suspeita de malignidade à elastografia, escore 3, duas (50\%) foram submetidas a excisão cirúrgica, que confirmou a benignidade, e para as outras duas (50\%) optou-se pelo acompanhamento, já que eram lesões estáveis por mais de dois anos.

Já a hiperplasia de células colunares típica revelou-se como cisto complexo pelo estudo ultra-sonográfico e como escore 4 à elastografia, indicando potencial de malignidade. Foi igualmente realizada excisão cirúrgica, que confirmou a origem benigna pela histologia, ou seja, foi o resultado falso-positivo encontrado pelo estudo. 

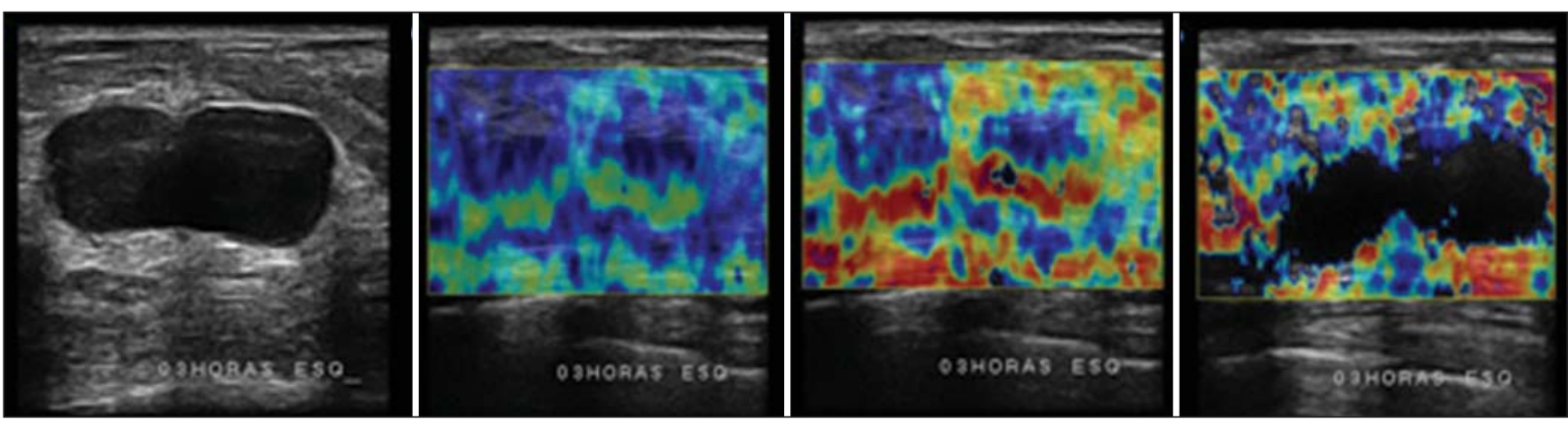

Figura 5. Cisto complicado ao modo convencional (imagem da esquerda) utilizando a elastografia durante a compressão (segunda imagem), após a descompressão (terceira imagem) e após compressão inadequada (imagem da direita). 0 cisto apresenta tipicamente o escore 2 pela elastografia, compatível com benignidade. Notar que quando a força é feita de forma inadequada, a área cística se apresenta enegrecida, sugerindo lesão sólida, provavelmente devido à tensão superficial do líquido.

Uma das limitações do estudo de lesões císticas pela elastografia é a quantidade de força utilizada para as compressões seriadas: quanto maior a força, aumenta-se a tensão superficial do líquido interno, determinando apresentação como sólida pelo espectro de cores (Figura 5). A vantagem é que, por ser um método em tempo real, o examinador pode medir a sua força durante a realização do exame e adequar-se para os diferentes tipos de mama e de lesões a serem estudadas. Esse aumento da tensão superficial do líquido intracístico pode também ser observado em lesões secretoras, como no caso da hiperplasia de células colunares e também em alguns cistos inflamatórios.

Estudos estão sendo realizados pelos autores para demonstrar a sensibilidade, especificidade e acurácia diagnóstica da elastografia, utilizando os critérios propostos pelos autores. Em dados preliminares em 170 nódulos, encontrou-se valor preditivo positivo de $80 \%$, especificidade de 97,5\% e acurácia diagnóstica de $97,7 \%$ para a classificação proposta.

Este estudo veio demonstrar que a elastografia pode auxiliar no diagnóstico de lesões mamárias císticas, confirmando a sua etiologia, e que, com a sua utilização na rotina clínica, poderia reduzir o número de biópsias desnecessárias e de acompanhamento de nódulos indeterminados pelo método convencional. Poderia também ser empregado como estudo complementar em cistos complexos para a avaliação de seu conteúdo interno, porém não contra-indicaria a realização de biópsia diagnóstica, já que nestes casos deve-se sempre valorizar os achados ao modo B.

\section{Agradecimento}

Agradecemos ao Núcleo de Apoio à Publicação da Faculdade de Ciências Médicas da Santa Casa de São Paulo (NAP$\mathrm{SC}$ ), pelo suporte técnico-científico à publicação deste manuscrito.

\section{REFERÊNCIAS}

1. Kasumi F. The diagnostic criteria for breast lesions of the Japan Society of Ultrasonics in Medicine and topical issues in the field of breast ultrasonography in Japan. In: Topics in breast ultrasound: Seventh International Congress on the Ultrasonic Examination of the Breast. Tokyo: Shinohara; 1991. p. 19-26.

2. Stavros AT, Thickman D, Rapp CL, et al. Solid breast nodules: use of sonography to distinguish between benign and malignant lesions. Radiology. 1995;196:123-34.

3. Kolb TM, Lichy J, Newhouse JH. Comparison of the performance of screening mammography, physical examination, and breast US and evaluation of factors that influence them: an analysis of 27,825 patient evaluations. Radiology. 2002; 225:165-75.

4. Kaplan SS. Clinical utility of bilateral wholebreast US in the evaluation of women with dense breast tissue. Radiology. 2001;221:641-9.

5. Berg WA, Campassi CI, Ioffe OB. Cystic lesions of the breast: sonographic-pathologic correlation. Radiology. 2003;227:183-91.

6. Buchberger W, Niehoff A, Obrist P, et al. Clinically and mammographically occult breast lesions: detection and classification with high-resolution sonography. Semin Ultrasound CT MR. 2000;21:325-36.

7. Soo MS, Ghate SV, Baker JA, et al. Streaming detection for evaluation of indeterminate sonographic breast masses: a pilot study. AJR Am J Roentgenol. 2006;186:1335-41.

8. Cha JH, Moon WK, Cho N, et al. Characterization of benign and malignant solid breast masses: comparison of conventional US and tissue harmonic imaging. Radiology. 2007;242:63-9.

9. Chang RF, Huang SF, Moon WK, et al. Solid breast masses: neural network analysis of vascular features at three-dimensional power Doppler US for benign or malignant classification. Radiology. 2007;243:56-62

10. Ophir I, Céspedes I, Ponnekanti H, et al. Elastography: a quantitative method for imaging the elasticity of biological tissues. Ultrason Imaging. 1991;13:111-34.

11. Ellis IO, Humphreys S, Michell M, et al. Best Practice No. 179. Guidelines for breast needle core biopsy handling and reporting in breast screening assessment. J Clin Pathol. 2004;57: 897-902.

12. Courtillot C, Plu-Bureau G, Binart N, et al. Benign breast diseases. J Mammary Gland Biol Neoplasia. 2005;10:325-35.

13. American College of Radiology. Breast Imaging Reporting and Data System ${ }^{\circledR}\left(\right.$ BI-RADS $\left.^{\circledR}\right)-$ ultrasound. 4th ed. Reston: American College of Radiology; 2003.

14. Kopans DB, Monsees B, Feig SA. Screening for cancer: when is it valid? Lessons from the mammography experience. Radiology. 2003;229:319_ 27.

15. Mendelson EB, Tobin CE. Critical pathways in using breast US. Radiographics. 1995;15:935-45.

16. Itoh A, Ueno E, Tohno E, et al. Breast disease: clinical application of US elastography for diagnosis. Radiology. 2006;239:341-50.

17. Hoyt K, Forsberg F, Ophir J. Analysis of a hybrid spectral strain estimation technique in elastography. Phys Med Biol. 2006;51:197-209.

18. Hall TJ. AAPM/RSNA physics tutorial for residents: topics in US: beyond the basics: elasticity imaging with US. Radiographics. 2003;23:165771.

19. Graf O, Helbich TH, Hopf G, et al. Probably benign breast masses at US: is follow-up an acceptable alternative to biopsy? Radiology. 2007;244: 87-93.

20. Moy L, Slanetz PJ, Moore R, et al. Specificity of mammography and US in the evaluation of a palpable abnormality: retrospective review. Radiology. 2002;225:176-81.

21. Kopans DB. Sonography should not be used for breast cancer screening until its efficacy has been proven scientifically. AJR Am J Roentgenol. 2004;182:489-91

22. Chala LF, Barros N. Avaliação das mamas com métodos de imagem. Radiol Bras. 2007;40(1):ivvi. 